\title{
LUZ MARÍA VILLARREAL DE PUGA
}

(1913-2013)

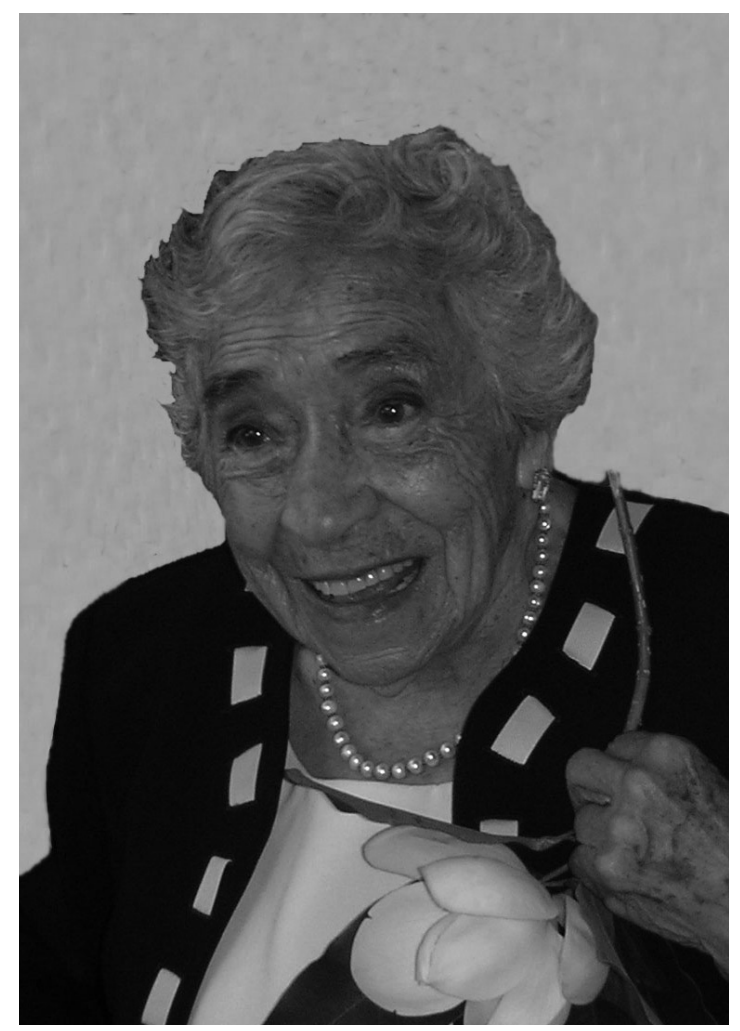

D rofesor emérito, Doctor Honoris Causa de la Universidad de Guadalajara y fundadora del herbario del Instituto de Botánica que lleva su nombre Luz María Villarreal de Puga (IBUG).

La maestra Puga como fue conocida, ocupó diversos cargos en esa casa de estudios, iniciando como catedrático en la Escuela de Trabajo Social (1964-1967) y después en los años setenta impartió clases de botánica general y sistemática en la escuelas preparatorias y de Agricultura y años más tarde en la División de Ciencias Biológicas del Centro Universitario de Ciencias Biológicas y Agropecuarias. Recientemente, el auditorio de este centro lleva su nombre, último acto académico al que pudo asistir. Fuera de la universidad por algunos años dio clases de ciencias naturales, botánica y zoología en la Escuela Normal Superior Nueva Galicia y Normal Superior de Jalisco.

En el período 1980-1992 fungió como director del Instituto de Botánica, un centro de investigación sobre el conocimiento de la flora del occidente de México y a partir de ese último año permaneció como director honorario vitalicio. En 1993, la universidad crea la "Presea Luz María Villarreal de Puga a la Excelencia en Biología" que se entregó a Rogers McVaugh. Después se hacen acreedores Hugh H. Iltis y Jerzy Rzedowski (1994), Roberto González Tamayo (1995), José Luis Navarrete (1996), Patricia Dávila Aranda (2000) Juan Luis Cifuentes Lemus y Graciela Calderón de Rzedowski (2001).

Con la participación de botánicos destacados mexicanos y de otros países, en 1998 se le dedicaron dos volúmenes del Boletín del Instituto de Botánica, por su octogésimo quinto aniversario. La misma revista, ahora con el nombre de ibugana, le consagro el número 4, para la conmemoración de su centenario.

Durante el transcurso de más de medio siglo, la maestra Puga participó en un sin número de ponencias, conferencias y entrevistas en relación al estudio de la flora jalisciense, sobre plantas medicinales y la defensa sobre la conservación de los recursos naturales.

Ella comenzó con sus primeras colectas de plantas en los inicios de la década de los sesentas, en la sierra del Tecuán (Jocotepec, San Juan Cosalá, Ajijic y Chapala), sierra de la Primavera, Zapopan y la barranca de Huentitán. Fue una apasionada por las plantas y siempre disfrutaba del campo, sobre todo en la compañía de sus discípulos. En su estudio por las plantas mexicanas ocupo su interés principal la familia Asteraceae. En 1994 obtuvo un reconocimiento por el herbario de la Escuela Nacional de Ciencias Biológicas (ENCB) del Instituto Politécnico como colector botánico. Ella permaneció activa hasta la edad de 95 años cuando dedicaba su tiempo al montaje de plantas para el herbario y disfrutaba atender visitantes a los que siempre les daba su clase de botánica. Se jubiló hasta septiembre de 2008. 
Una de sus obras quizás la más importante, fue la de formación de recursos humanos. Ella siempre decía con orgullo "mis alumnos ahora son mis jefes". Durante toda su trayectoria le concedieron innumerables distinciones por su brillante labor académica, además de premios, reconocimientos y homenajes por la Universidad de Guadalajara, diversas instituciones, asociaciones, así como del gobierno del Estado de Jalisco y de la República Mexicana.

Socia honoraria y vitalicia de la Sociedad Botánica de México, A.C. quién le otorgó varios reconocimientos por su especial contribución a la investigación botánica en México, la defensa de la Sierra de Manantlán y la formación de las nuevas generaciones de estudiosos. En 1989 recibe la litografía de Castilla elastica otorgada a los principales botánicos que han contribuido al conocimiento de la Flora de México, con motivo del bicentenario de la instauración de la primera cátedra formal de botánica en México (1788-1988).

La Benemérita Sociedad de Geografía y Estadística del Estado de Jalisco, A.C. también le concede diversos reconocimientos, entre los que destacan, la "Presea Severo Díaz Galindo" (1989) como primer mujer que ingresó a la sociedad. En 2001 obtiene la medalla al mérito "Benito Juárez" por su valioso aporte a la promoción en la cultura y el desarrollo científico. En 2004 el reconocimiento como Tlamatini "Tesoro Viviente de México", la junta Directiva Nacional le confiere el ingreso a la orden de los Tlamatinimeh.

Del gobierno del estado de Jalisco recibe condecoraciones por sus servicios prestados a la educación pública y su destacada labor magisterial. En el Año Internacional de la Mujer (1975) adquiere la medalla Mujer y Madre, Símbolo de la Patria. En 1991 gana la condecoración Manuel López Cotilla y en 1999 la medalla Ciudad de Guadalajara. En 1987 obtiene del Presidente de la República Mexicana, Miguel de la Madrid un reconocimiento por su participación en la defensa, conservación y preservación de los recursos naturales de la Sierra de Manantlán. En 1994 le conceden el Premio al Mérito Nacional Forestal y de la Vida Silvestre en la categoría de Fomento de Flora por ser un pilar de la botánica en México y por su destacada contribución al conocimiento de los maíces silvestres, entregado por el Presidente de la República Mexicana, Carlos Salinas de Gortari. Ella fue una de las artífices del descubrimiento de Zea diploperennis, una especie de maíz primitivo que dio pie a la declaratoria de la Reserva de Manantlán. En 1997 recibió del Presidente Ernesto Zedillo Ponce de León el Premio Jalisco en Ciencias. También, el Consejo Nacional de Ciencia y Tecnología le da un reconocimiento al Mérito Científico 2000, la estatuilla Diosa Atenea, por la distinción a la excelencia académica y científica.

Fue una persona muy querida entre los botánicos mexicanos y extranjeros quienes le han dedicado 25 especies que pertenecen a dieciséis familias de plantas vasculares y un hongo alucinógeno que llevan su nombre en diferentes epítetos. Rogers McVaugh (1993) dedica en su honor el volumen 13 Limnocharitaceae to Typhaceae de la Flora Novo-Galiciana.

La maestra Puga fue una incansable exploradora e investigadora de la Flora de Jalisco, así como asidua defensora de la Sierra de Manantlán. Ella fallece el 11 de noviembre de 2013, fue cremada y sus cenizas serán dispersadas en la sierra por la que luchó para que se decretara como reserva de la biosfera.

Maestra Luz María González-Villarreal

Instituto de Botánica

Universidad de Guadalajara 